\title{
Impact of the Change in Payments on the Actual and Perceived Behaviors of Medical Care Providers
}

\author{
Amy Eremionkhale \\ Georgia State University
}

Prior literature established the link between a person aging out of a parent's insurance coverage at age nineteen and a significant decrease in insurance coverage of those nineteen-year-old young adults. This paper furthers this line of research by establishing a statically significant change in the payment burden of the various sources that comprise the total payment received by the medical care providers treating young adults who have aged out of their parent's insurance. The empirical method used is the regression discontinuity framework. The impact of the change in the providers' payment sources on the providers' behavior (supply-side) and the patients' perception of the providers' behavior (demand-side) is examined using a 14-year sample of unmarried young adults from the Medical Expenditure Panel Survey. This research finds that although there is a statistically significant change in the sources of the total payments received by medical care providers, they do not change their actual treatment decisions. However, the patients do perceive a statistically significant adverse change in the behavior of their medical care providers.

Keywords: health insurance, patient's perception, treatment decisions, medical care providers behavior, age-out policy

\section{INTRODUCTION}

The recent repeal of the individual mandate of the Patient Protection Affordable Care Act (PPACA), which was implemented in 2010, has made it essential to study the impact of having and then losing health insurance coverage on both patients and providers. This paper investigates how a change in the payments received by medical care providers affects their treatment decisions and their behavior as perceived by their patients. Patients' perspectives on their medical treatment experience have received considerable prominence in the evaluation of modern healthcare, with these subjective appraisals being viewed as valuable health outcomes. (Boquiren et al., 2015; Kupfer and Bond, 2012; Squires, 2012; Riiskjær et al., 2010; Freeman, 2002)

This research takes advantage of the pre-2010 law, which specifies that young adults aged out of their parent's insurance plan at nineteen. Existing literature shows a sharp drop in insurance coverage rates (Andrews, 2013; Palmieri, 2017). I use the loss of insurance coverage as a natural experiment that identifies the change in the payments received by their medical care providers. I study the treatment and perceptions of a sample of unmarried young adults, excluding full-time students, from the Medical Expenditure Panel Survey (MEPS). The sample period begins in 1996, the earliest year available, and ends in 2009, before the 2010 Affordable Care Act. 
Firstly, I establish that although the total payments received by the providers did not change, the amounts received from the different payment sources changed as the young adults' aged-out of their parent's insurance. I use a regression discontinuity to correct for the possible endogeneity of provider payments. Provider payments may be endogenous because it is likely correlated with any unobserved provider and patient preferences. However, the aging-out policy exogenously determines the patients' insurance status, affecting how medical treatments will be paid. This change in insurance status is not related to the physicians' preference or patient preference but rather is determined by the natural process of aging and therefore is an exogenous shock to the payments received by providers. I then investigate the impact of the change in the provider's payments on their treatment decisions and the patients' perception of their behavior. In the regression discontinuity framework, I compared the treatment and experiences of those just above nineteen to those of the young adults just below nineteen because these two groups should be very similar within a narrow bandwidth. To confirm the similarity between the two groups, I performed a smoothness test of other characteristics within a bandwidth of twelve months, just above and just below the age of nineteen. The observable characteristics are smooth across the threshold of age nineteen, as discussed below.

This paper makes three contributions to the current literature on how providers' payments affect their treatment decisions. In this research, although there are statistically significant changes in the amount paid to the providers' payments from the different sources, there is no statistically significant change in the providers' treatment decisions. Secondly, this paper contributes by investigating the patients' perception of their providers' behaviors. I find a statistically significant change in the patients' perception of their providers' behaviors as the payments made to their providers change. This change in perception is for the worse, as patients perceive that their providers are less respectful of them, spend less time with them, and do not listen to them as much as they did before the change in the providers' payments. This contribution is essential because these changed perceptions may affect trust and follow up in the treatment plan. Finally, I make a methodological contribution in applying regression discontinuity to examine the causal relationship between the payments received by providers from the different sources, the treatment decision of the providers, and their patients' perception.

\section{DATA}

\section{Data Description}

I use data on individual office visits from the Medical Expenditure Panel Survey (MEPS) for the analysis. The Medical Expenditure Panel Survey (MEPS) is a set of large-scale nationally representative surveys of families and individuals, their medical providers, and employers across the United States (AHRQ, 2009) and is a complete source of data on the cost and use of health care and health insurance coverage available. MEPS has been used extensively in scientific publications and published reports and by the Federal and state governments to examine the delivery and financing of health care in the United States (Cohen et al., 2009; AHRQ, 2018; Wang et al., 2006).

I use data from two of the MEPS surveys: a household survey and a survey of medical providers (provider refers to a combination of Physicians and Non-Physicians, e.g., RN, LPN, PA, etc.). The Household Component ${ }^{1}$ collects data from a new panel of sample households each year. The data for each panel is organized over two calendar years in five rounds of interviews. Each round of MEPS-HC interviews collects information on a specific period called a reference period (AHRQ, 2015; Cohen et al., 2009; Harrison et al., 2018).

The Office-Based Medical Provider Visits File ${ }^{2}$ provides detailed information on office-based provider visits for a nationally representative sample of the civilian non-institutionalized population of the United States (AHRQ, 2014). I combine data from these two survey files using the person identifier, DUPERSID, to develop my sample for each year. 


\section{Analysis Sample}

The sample comprises data from 1996, the earliest available data through 2009, the last year before the implementation of the PPACA. I extract data on unmarried young adults who are not full-time students because the age-out policy did not apply to full-time students (Healthcare.gov, 2012; Anderson et al., 2012). I can measure the age of the young adults used in my analysis in months because MEPS data include each patient's birth month and year and the month and year in which each office-based visit occurred. In the 14year sample, there are 7,912 office-based visits within the bandwidth of 12 months on either side of age 228 months for the young adults. The threshold age is 228 months ( 19 years $\times 12$ months), with observations on young adults in the age range of 216 months and 240 months.

Each observation in the sample represents one office visit and includes information on the patient's demographics, the ICD9 condition addressed during that visit, and the payments for care provided, including out-of-pocket payments, payments by private insurance, Medicaid, and other sources. To minimize the influence of outliers, I exclude visits with total payments greater than $\$ 300$, which represented the approximate value for the 95th percentile of the total payments.

\section{EMPIRICAL FRAMEWORK AND ESTIMATION}

\section{Empirical Framework}

The following model is estimated using the Ordinary Least Squares (OLS) method. The bandwidth is limited to twelve months around the age 228 months threshold, and the regressions take the form:

$$
\begin{aligned}
Y_{i v r t} & =\alpha_{0}+\alpha_{1} A O_{i v r t} \times(\text { age } \\
& +\alpha_{3}\left(1-A O_{i v r t}-228 m o n t h s\right) \times(\text { age }) \\
& \left.+I C D 9 C C I 0_{i v r t}+228 \text { months }\right)+\delta X_{i v r t}+\alpha_{r}+\mu_{i v r t}
\end{aligned}
$$

where $\mathrm{Y}$ represents an outcome or treatment measures for patient $\mathrm{i}$ at visit $\mathrm{v}$ in region $\mathrm{r}$ in year $\mathrm{t}$, the treatment measures are the payments received by the medical care providers. The total payments received by the provider for each office-based visit are comprised of payments from different sources, including private insurance, Medicaid, out-of-pocket (from the patients), and other sources. The second measure of payments I use in this analysis is the sum of the amounts received from private insurance and Medicaid for each visit. The age-out policy affected young adults with coverage from either their parent's private insurance or coverage from Medicaid. In addition to these total payment values, I include the payments received by the providers separated by the source to analyze better the nuanced changes occurring in the providers' payments. The summary statistics of these variables are shown in the section of table 1 .

The outcome variables are comprised of the provider treatment decision measures and the patient perception measures. The provider decisions measured are indicator variables: "Any Medicine Prescribed", "Lab Tests", and "Other Diagnostic Test/Exam". Respectively, these variables equal one if medicine was prescribed during the visit or lab tests were done. Other relatively more time-consuming diagnostic tests/exams ${ }^{3}$ were performed during the office-based visit. The patients' perception outcome measures are indicator variables: "Enough Time", "Listen", and "Respect", that equal one if the patient reported that the provider spent enough time with them during the visit, listened to them, and showed them respect during the office-based visit.

$A O$ stands for Age-Out and is an indicator variable that equals one if the individual $\mathrm{i}$ is older than 228 months at the time of the visit, $v$. The estimated coefficient of this variable, $\alpha_{1}$, represents the estimated discontinuity of interest the age threshold for each of the outcome and treatment variables. The variable age defines the age of individual $i$ at year $t$ at the time of the visit $v$ measured in months. ${ }^{4}$ The use of the month unit of measure is appropriate for this study because many private and some public health plans cover dependents through the last day of the month in which the dependent turns 228 months (Anderson et al., 2012; Collins et al., 2008). ${ }^{5}$ Separate age trend terms above $\left[\left(\mathrm{AO}_{\mathrm{iv}}\right) \times\left(\mathrm{age}_{\mathrm{iv}}-228\right.\right.$ months $\left.)\right]$ and below [(1 $\left.\left.-\mathrm{AO}_{\mathrm{iv}}\right) \times\left(\mathrm{age}_{\mathrm{iv}}-228 \mathrm{months}\right)\right]$ the age cutoff are included in the model and parameterized so that $\alpha_{2}=\alpha_{3}$ if the trend is the same above and below the cutoff (Almond et al., 2010). 
$\mathrm{X}_{\mathrm{iv}}$ is a vector of the demographic variables for everyone in the sample. The demographic variables used in this analysis are race (equals one if the patient is White and zero otherwise), gender (equals one if the individual is female, and zero otherwise), ethnicity (equals one if the patient is Hispanic and zero otherwise). The demographic vector also includes the individual's employment status (equals one if the patient is employed, either full-time or part-time employed and zero if unemployed), marital status (equals one if a patient is married and zero otherwise ${ }^{6}$ ), and personal income.

The conditions treated in each visit are represented using the International Classification of Diseases, Ninth Revision, Clinical Modification (ICD-9-CM) condition codes which have been aggregated into clinically meaningful categories that put similar conditions into a group (CCCODEX) (AHRQ, 2008) ${ }^{7}$. These conditions are grouped using the Charlson Comorbidity Index (CCI). The indicator variable, ICD9CCI-0, equals zero for observations with CCI values greater than zero and equals one for the observations with a CCI value of zero (Roffman et al., 2016). Finally, the model also includes the year ( $\alpha \mathrm{t})$ and region ( $\alpha$ r) fixed effects. The regions in the sample are Northeast, Midwest, South, and West. All estimations of equation (1) are weighted using the final person weight, called PERWTF, in the household component data of MEPS. The standard errors are clustered by ages, measured in months (Lee and Card, 2008).

TABLE 1

\section{SAMPLE SUMMARY STATISTICS}

\begin{tabular}{|c|c|c|c|c|}
\hline & \multicolumn{2}{|c|}{ Entire Sample } & \multicolumn{2}{|c|}{ Before 228 Months } \\
\hline & Mean & Std. Dev. & Mean & Std. Dev. \\
\hline Payment Variables: & $(1)$ & $(2)$ & $(3)$ & (4) \\
\hline Total Payment From All Sources $(\$)$ & 67.31 & 57.99 & 68.85 & 57.38 \\
\hline Total Payment from Private Insurance \& Medicaid (\$) & 42.72 & 53.92 & 46.60 & 54.98 \\
\hline Payment by Sources: & & & & \\
\hline Out-of-Pocket (\$) & 14.68 & 33.74 & 12.58 & 28.56 \\
\hline Private insurance $(\$)$ & 21.96 & 42.84 & 26.31 & 46.12 \\
\hline Medicaid (\$) & 20.84 & 44.58 & 20.43 & 44.40 \\
\hline Others $(\$)$ & 9.83 & 31.75 & 9.53 & 31.27 \\
\hline Outcome Variables - Treatment Decisions: & & & & \\
\hline Any Medicine Prescribed & 0.2859 & 0.45 & 0.2998 & 0.46 \\
\hline Lab Tests & 0.2425 & 0.43 & 0.2331 & 0.42 \\
\hline Other Diag Test/Exam & 0.1124 & 0.32 & 0.1179 & 0.32 \\
\hline Outcome Variables - Patients' Perception: & & & & \\
\hline Enough Time & 0.4082 & 0.49 & 0.4033 & 0.49 \\
\hline Listen & 0.4453 & 0.50 & 0.4336 & 0.50 \\
\hline Respect & 0.4621 & 0.50 & 0.4530 & 0.50 \\
\hline Control Variables: & & & & \\
\hline Female & 0.6527 & 0.48 & 0.6342 & 0.49 \\
\hline Nonwhite & 0.1830 & 0.39 & 0.1819 & 0.39 \\
\hline Hispanic & 0.2781 & 0.45 & 0.2514 & 0.43 \\
\hline Employed & 0.7424 & 0.44 & 0.7243 & 0.45 \\
\hline Personal Income & 7521 & 8314 & 6239 & 7037 \\
\hline ICD9-CCI-0 & 0.97 & 0.93 & 0.98 & 0.94 \\
\hline
\end{tabular}

The reduced form estimates of the direct impact of the AOiv indicator on the treatment and outcome measures are reported separately. This paper identifies the causal effect of the change in payments on medical care providers' actual and perceived behaviors by combining the outcome and treatment estimates (Almond et al., 2010). In the language of instrumental variables, the discontinuities in actual provider 
behavior and patient-perceived provider behaviors are the reduced-form estimates. The discontinuity in provider payments is the first-stage estimate. There are several ways to compute the IV estimator (Cameron and Trivedi, 2017). I calculate the estimator as:

$$
\begin{aligned}
d z & =\frac{\frac{d y(\text { outcome })}{d z}}{\frac{d y(\text { treatment })}{d z}}=\frac{\frac{d(" \text { Any Medicine Prescribed })}{d(\text { AO })}}{\frac{d y(\text { payments })}{d(\text { AO })}} \\
& =\frac{\alpha_{1}(\text { "Any Medicine Prescribed") }}{\left.\alpha_{1} \text { (payments }\right)}
\end{aligned}
$$

$\beta$ is the primary impact measure of concern in this research. It measures the effect of a change in the providers' payments on the actual and perceived behaviors of the providers. The reduced form estimates of the impact of turning 228 months on the various outcome variables and treatment variables.

In this framework, the instrument is the $\mathrm{AO}$ indicator. For the $\mathrm{AO}$ indicator to be a valid instrument, a solid first-stage relationship must exist between the AO indicator and the measure of the per-visit provider revenue; note that this relationship will be conditional on our running variable (age in months). Also, the exclusion restriction requires that the only mechanism through which the instrument $\mathrm{AO}$ indicator affects the actual provider behaviors and patient perception outcomes, conditional on age-in-months falling within the bandwidth, is through its effect on the provider's payments (Cameron and Trivedi, 2017; Almond et al., 2010; Schmidheiny, 2018). The only way turning 228 months old affects actual and perceived medical provider behavior is through its effect on payments.

\section{Smoothness Criteria}

The existence of smooth observable characteristics validates the exclusion restriction. The discontinuous change in revenue we observe at the age threshold is due only to the discontinuous change in insurance status at age 228 months and not due to any discontinuous changes in other characteristics (Anderson et al., 2012; Almond et al., 2010; Lee and Lemieux, 2010; Imbens and Lemieux, 2008). The exclusion restriction states that no variables other than the one affected by the natural experiment changed discontinuously across the threshold (McCrary, 2007; Zuckerman et al., 2006; Trochim, 1984).

These continuity assumptions might not be plausible if the young adults could manipulate the running variable; their age (McCrary, 2007; Almond et al., 2010; Anderson et al., 2012). However, the age of the young adults cannot be reasonably manipulated because we measure age at the monthly level in our analyses (Ander- son et al., 2012). This fact implies that the most apparent confounders, especially high school graduation or commencement of employment, should not bias the estimates. For example, high school graduations occur in June, but nineteenth birthdays are distributed throughout the year. Thus, the high school graduation rate should not change discontinuously in the month following an individual's nineteenth birthday. Table 2 and Figure 1 show the check of smoothness.

The last two columns of table 2 show that the smoothness of these factors exists in this paper's analysis. The observable characteristics of the young adults and the conditions treated are similar for the patients on either side of the 228-month threshold. These columns report regression coefficients and standard errors (SE) from setting the observable characteristics as the $\mathrm{Y}$ variables in equation 1. 
TABLE 2

MEANS BEFORE \& AFTER CUTOFF: SMOOTHNESS TESTS

\begin{tabular}{|c|c|c|c|c|}
\hline & $\begin{array}{l}\text { Mean } \\
\text { Below } \\
\text { Cutoff } \\
(1)\end{array}$ & $\begin{array}{l}\text { Mean } \\
\text { After } \\
\text { Cutoff } \\
(2)\end{array}$ & $\begin{array}{c}\text { Regression estimates of } \\
\text { discrete jump at } 228 \\
\text { months } \\
\text { (1-year bandwidth) } \\
\text { (3) }\end{array}$ & $\begin{array}{l}\text { SE for difference estimates } \\
\text { in RD } \\
\text { (4) }\end{array}$ \\
\hline Female & 0.63 & 0.67 & 0.03 & {$[0.032]$} \\
\hline Nonwhite & 0.18 & 0.18 & -0.01 & {$[0.022]$} \\
\hline Hispanic & 0.25 & 0.29 & 0.04 & {$[0.024]$} \\
\hline Employed & 0.72 & 0.76 & 0.04 & {$[0.035]$} \\
\hline Personal Income & 6239 & 8722 & 150.62 & [676.38] \\
\hline ICD9-CCI-0 & 0.98 & 0.96 & 0.00 & {$[0.010]$} \\
\hline
\end{tabular}

Notes: The standard errors are clustered at the age level, measured in months. The differences and related standard errors are estimated using McCary (2008) by regressing each of these demographic variables in the same framework as our regression discontinuity estimates. These difference estimates are also weighted using the individual sample weights assigned in MEPS. The model is estimated on a sample within 12 months above and below the age 228 months threshold. The controls used in this model include year indicators from 1996 to 2009 and the region indicators for Northeast, West, Midwest, and South regions.

\section{FIGURE 1}

\section{COVARIATES AROUND 228 MONTHS}
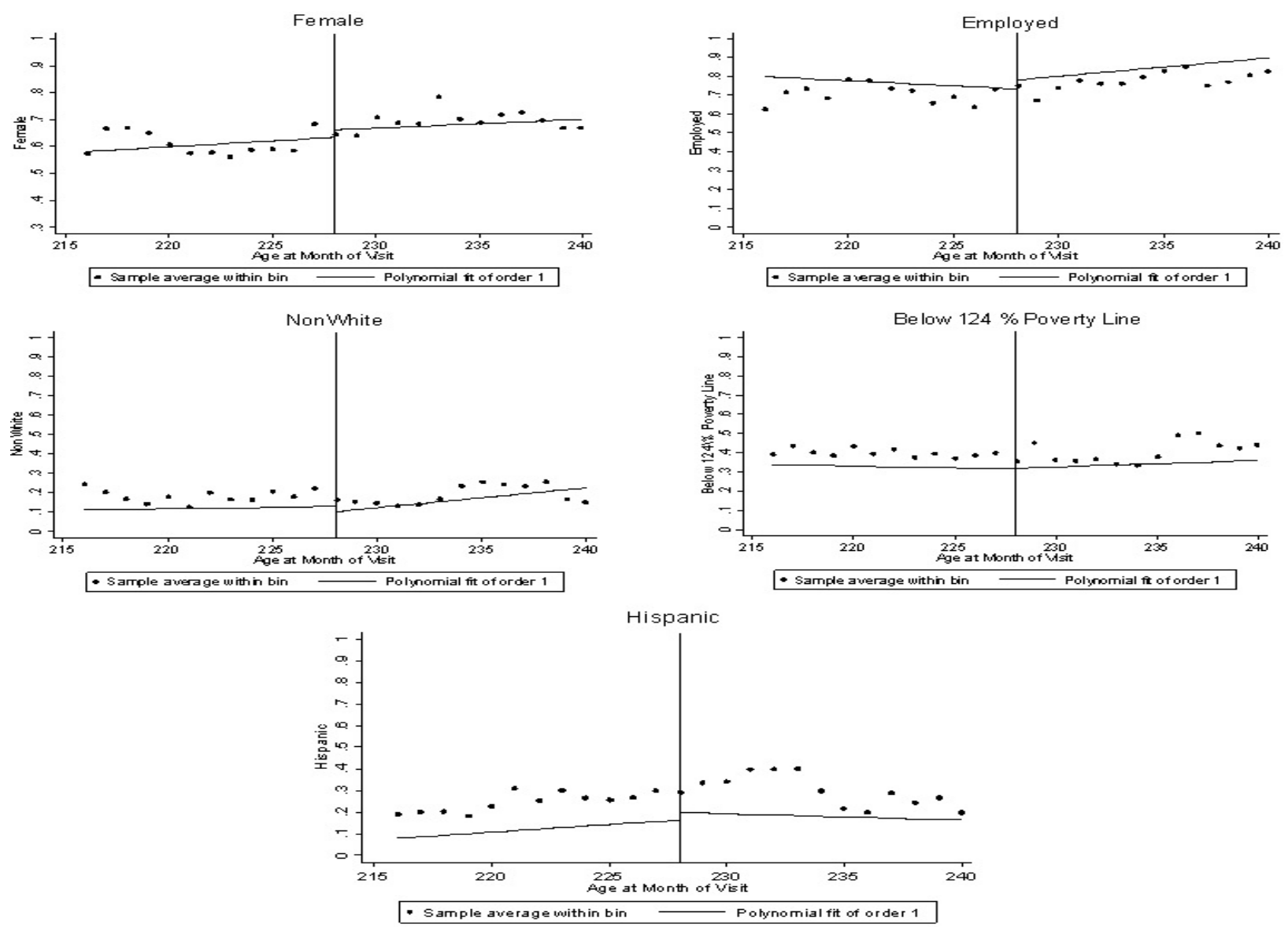

202 Journal of Applied Business and Economics Vol. 23(4) 2021 


\section{RESULTS}

Figure 2 shows the payments by sources received by the medical care providers around the 228-month threshold. The figure shows no noticeable change in the total payment received by the providers for each visit. There does, however, appear to be a significant decrease in the total amount received from private insurance and Medicaid sources combined. The most considerable change seems to be the decrease in the amount sourced from private insurance. The payments received from the patients' out-of-pocket source visually show a jump across the threshold.

Figure 3 presents the three measures of the providers' actual treatment decisions around the age threshold. There is no noticeable increase or decrease in the measures of the providers' treatment decisions. The three variables for the patients' perception of their providers' behavior is shown in Figure 4. Here, there does appear to be an apparent decrease for all three variables across the threshold. Inspection of these figures reveal that there may be strong effects in the payments and the patients' perceptions, but not in the actual treatment decisions.

FIGURE 2

PAYMENTS AROUND 228 MONTHS
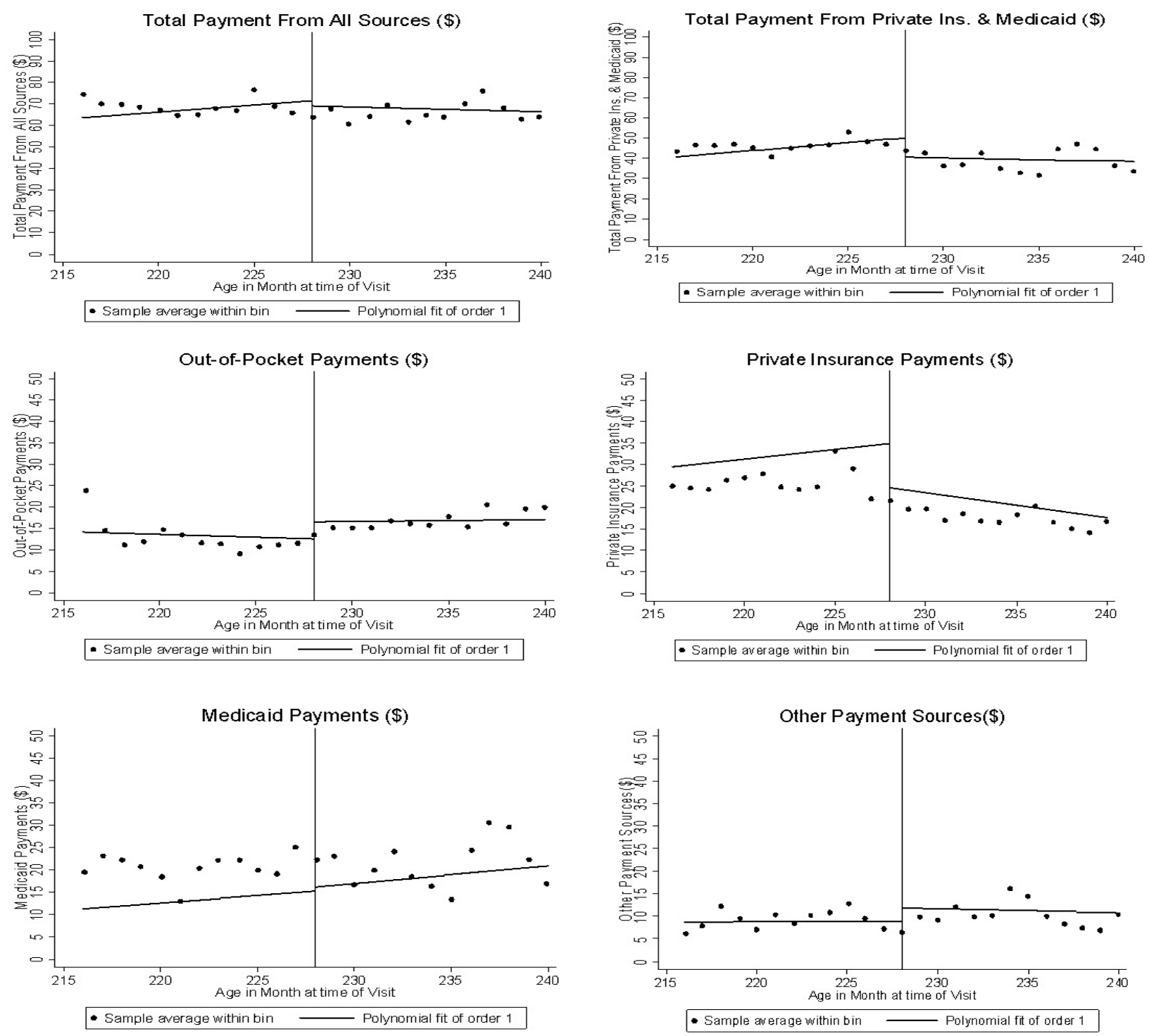
FIGURE 3

ACTUAL CHANGE IN THE PROVIDERS' TREATMENT DECISIONS AROUND 228 MONTHS
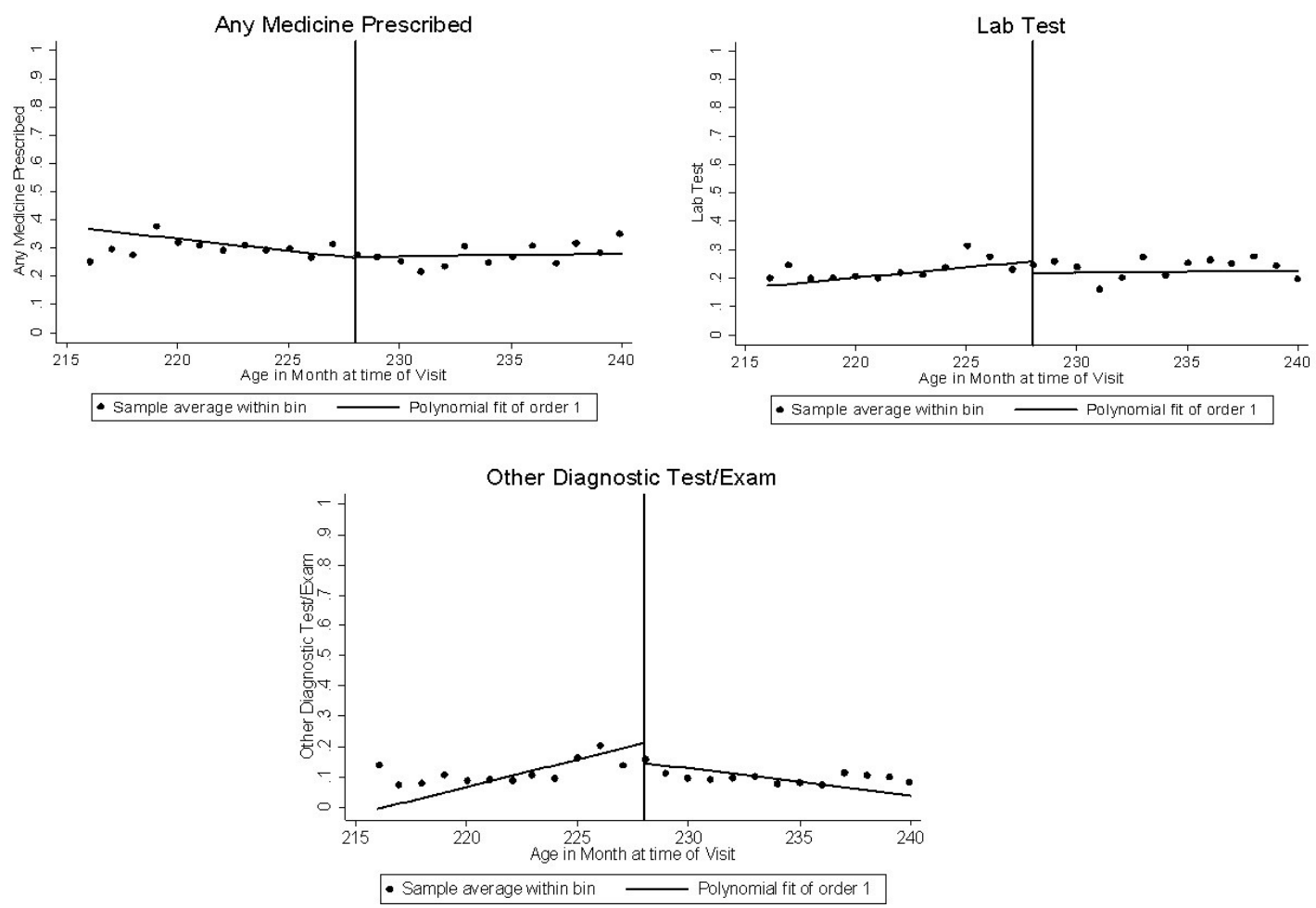

FIGURE 4

PERCEIVED CHANGE IN THE PROVIDERS' BEHAVIOR AROUND 228 MONTHS
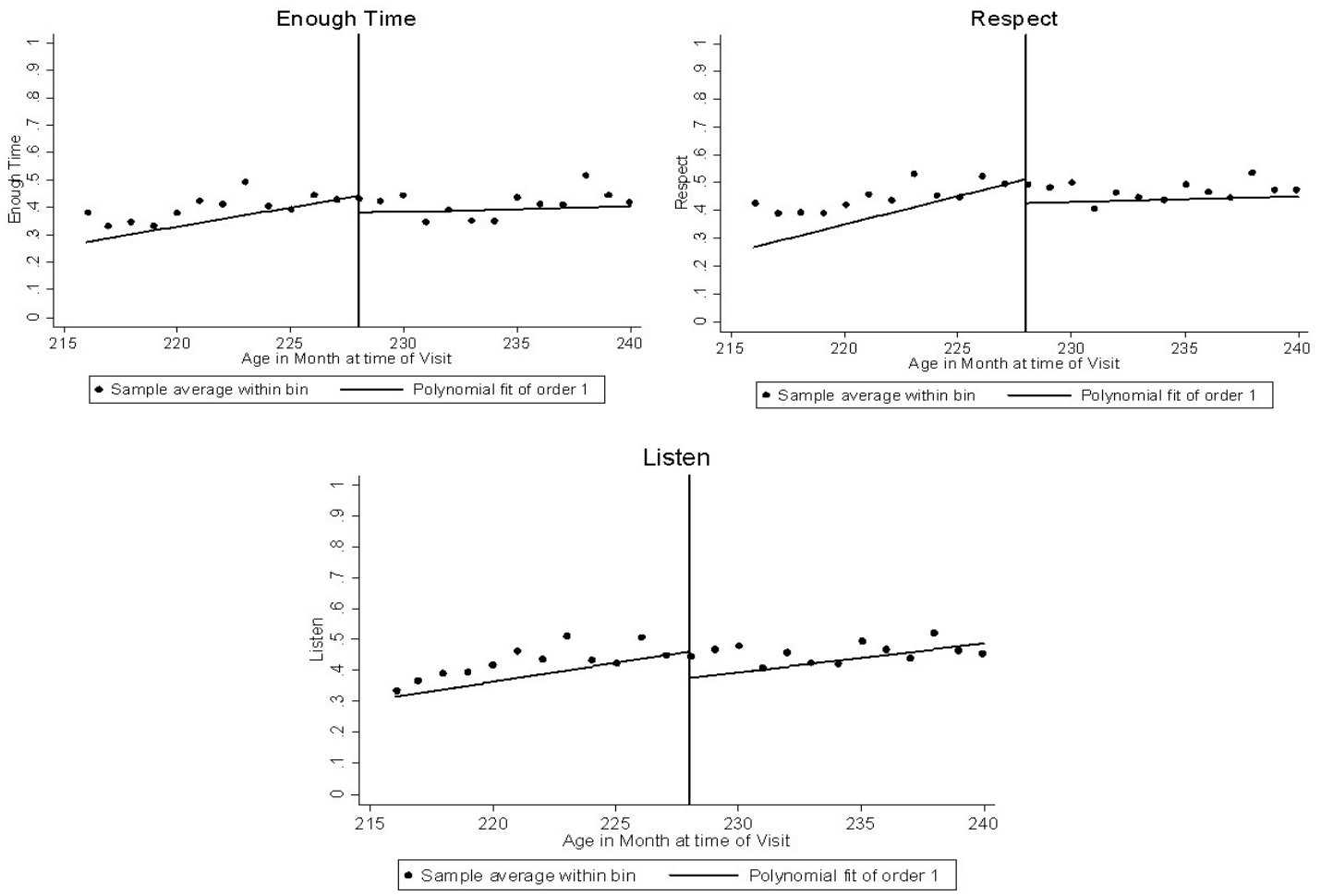

204 Journal of Applied Business and Economics Vol. 23(4) 2021 


\section{Change in Medical Providers' Payments Across Threshold - Treatment Variable}

The estimated impact of aging out on payment sources is shown in Table 3. The results show a statistically significant decrease in the sum of the payments received by medical care providers sourced from private insurance and Medicaid in the amount of $\$ 7.61$ across the age threshold. The estimated change

implies a $16.33 \%=\left(\frac{7.614}{46.60}\right)$ reduction in the payments compared to a mean of $\$ 46.60$ for the twelve months below the threshold (the "untreated" group in this regression discontinuity design). The providers' total payment from all sources does not change statistically significantly as the young adults age out of their parent's insurance coverage.

There is a statistically significant increase in the medical providers' per-visit revenue sourced from the out-of-pocket payments made by the patients of $\$ 5.77$. This amount represents a $45.87 \%$ increase compared to the mean of $\$ 12.58$ for the twelve months before the age 228 -month threshold. The payments sourced from private insurance decreased statistically significantly by $\$ 9.986$. This decrease is a $37.96 \%$ drop in the payment sourced from private insurance, compared to the "before" average of $\$ 26.31$. There is no statistically significant change in the amounts received from the other payment sources. These results are supported by the findings in previous literature on the drop in insurance coverage that occurs across the threshold of age 228 months (Anderson et al., 2012).

Therefore, when there is a loss of insurance coverage induced by the natural experiment (aging-out policy), the medical care providers do not lose a statistically significant amount of their total per-visit revenue. However, the patients pay $45.87 \%$ more money out of pocket than before aging out, and payments from private insurance companies decrease by a statistically significant $37.96 \%$.

\section{Change in the Providers' Treatment Decisions}

Table 3 presents the estimates of changes in three provider treatment decisions, "Any Medicine Prescribed", "Lab Tests", and "Other Diagnostic Test/Exam". From Table 1, you can see that providers prescribed medicine during $28.58 \%$ of their office-based visits. The estimated change in the prescribing behavior of medical care providers across the threshold is -0.036 . This result is not statistically significant, which implies that there is no discontinuous change in the prescription behavior of medical care providers across the age threshold of 228 months.

The mean of the second treatment variable is 0.2425 , which implies that a lab test occurred for $24.25 \%$ of the visits in the sample, as shown in Table 1. The estimated change in lab tests across the threshold is 0.039 and is not statistically significant. This result implies that providers do not change their treatment behavior related to the number of visits where lab tests are performed. The mean of the third variable, "Other Diagnostic Test/Exam", shows that some diagnostic tests or exams other than lab tests were performed in $11.24 \%$ of the visits (as shown in Table 1). The estimated change in the occurrence of other diagnostic tests and exams during an office-based provider visit is -0.045 , with a standard error of 0.036 . It is, therefore, not statistically significant. Medical care providers did not significantly decrease their use of other diagnostic tests and exams during visits across the age threshold. Overall, medical care providers do not change their treatment decisions as their patients age across the threshold of 228 months.

\section{Patient Perception of Change in Providers' Behaviors}

The mean of the first patient perception variable, "enough time", is $40.82 \%$ (Table 1). The estimated change in this variable across the age 228 months threshold is -0.079 percentage points with a standard error of 0.031 , making it statistically significant at the $5 \%$ level of significance, as shown in Table 3 . This statistically significant decrease represents a $19.59 \%=\left(\frac{0.079}{0.4033}\right)$ decrease relative to the mean of $40.33 \%$ from the twelve months before 228 months. The mean of the second variable, "Listen", shown in Table 1, indicates that patients felt listened to in $44.52 \%$ of the office-based visits. The estimated change in this patient perception variable is -0.105 percentage points with a standard error of 0.028 , which is statistically significant at the $1 \%$ significance level. This estimate represents an approximate decrease of $24.22 \%$ in the visits where patients felt the provider listened to them, relative to the average of $43.36 \%$ from the twelve months below the threshold. 
The mean of the third variable, "Respect", shown in Table 1, is $46.21 \%$. The estimated change in this perceived variable is -0.091 . It is statistically significant at the $5 \%$ level of significance. The estimate represents an approximate decrease of $20.09 \%$ in the visits where providers felt respected by their provider, relative to the below 228-month threshold average of $45.30 \%$. Overall, the results reported in table 3 show that across the threshold of age 228 months, patients felt significantly less satisfied with their provider's behavior. Once they turned 19, the patients felt that the medical providers spent less than enough time with them; they felt less respected and felt the providers did not listen to them as much.

\section{TABLE 3 \\ REDUCED FORM ESTIMATES}

\begin{tabular}{|c|c|c|}
\hline & $\begin{array}{c}\text { Age }>228 \text { months }\left(\alpha_{1}\right) \\
(1)\end{array}$ & $\begin{array}{l}\mathrm{SE} \\
(2)\end{array}$ \\
\hline \multicolumn{3}{|l|}{ Payment Variables: } \\
\hline Total Payment from All Sources $(\$)$ & 0.899 & [3.462] \\
\hline Total Payment from Private Insurance \& Medicaid (\$) & $-7.614 * * *$ & [2.148] \\
\hline \multicolumn{3}{|l|}{ Payment by Sources: } \\
\hline Out-of-Pocket (\$) & $5.771 * * *$ & [2.018] \\
\hline Private Insurance (\$) & $-9.986 * * *$ & [2.325] \\
\hline Medicaid (\$) & 2.474 & [2.150] \\
\hline Others $(\$)$ & 2.640 & [1.894] \\
\hline \multicolumn{3}{|l|}{ Outcome Variables - Treatment Decisions: } \\
\hline$\overline{\text { Any Medicine Prescribed }}$ & -0.036 & [0.029] \\
\hline Lab Tests & -0.039 & [0.035] \\
\hline Other Diag Test/Exam & -0.045 & {$[0.036]$} \\
\hline Actual Time Spent (1996-2000) & -0.413 & [2.058] \\
\hline \multicolumn{3}{|l|}{ Outcome Variables - Patients' Perception: } \\
\hline Enough Time & $-0.079 * *$ & [0.031] \\
\hline Listen & $-0.105 * * *$ & [0.028] \\
\hline Respect & $-0.091 * *$ & {$[0.034]$} \\
\hline Year Controls & Yes & \\
\hline Region Controls & Yes & \\
\hline Condition Control & Yes & \\
\hline Observations & 7,912 & \\
\hline Weighted & Yes & \\
\hline Bandwidth & 12 Months & \\
\hline
\end{tabular}

Notes. The standard errors are clustered at the age level, measured in months. Clustered standard errors in brackets $\left({ }^{* * *} \mathrm{p}<0.01, * * \mathrm{p}<0.05, * \mathrm{p}<0.1\right)$. The model is estimated on a sample within 12 months above and below the age 228-month threshold. The control variables used in these regression models include year indicator variables for the years 1996 to 2009, region indicator variables for the Northeast, West, Midwest, and South regions. The demographic variables of the individuals in the sample controlled in the model are gender, race, socio-economic status, ethnicity, and employment status. The conditions addressed during each visit as categorized by ICD9 codes are also controlled for in the model. The data are weighted using the reported final person weight assigned to each individual. The data is sourced from MEPS administered by AHRQ.

\section{Impact of the Change in Provider Payments on the Actual and Perceived Behavior of Medical Care Providers}

This section discusses the analogous instrumental variable estimates, $\beta$, which are reported in table 4 . The table shows the providers' payments by sources have on the provider's actual and perceived behaviors across the discontinuity. All specifications include before and after trends, year trends, conditions, and other covariates. The estimated changes are reported for a $\$ 10$ change in the payments received by the provider. 
The first three columns of table 4 show the effect of the change in total payment on the actual treatment decisions of medical care providers. The standard errors of these $\beta$ s are derived using the propagation of error (Chemistry-LibreTexts, 2018). ${ }^{8}$ The last three columns of table 4 show the effect that each source's change in the providers' payments has on the patients' perception of their provider's behavior. The results show that a $\$ 10$ decrease in total per-visit payment does not lead to a statistically significant change in any of the measured provider's treatment decisions. The full payment for each visit received by the medical care provider is the only payment measure used to investigate the impact on the actual treatment decision of the providers.

A $\$ 10$ decrease in the payments from the sum of private insurance and Medicaid sources leads to a statistically significant reduction of $0.1038,0.1379$ and 0.1195 percentage points in the visits where the young adults felt that their provider spent enough time with them, listened to them and respected them, respectively. This result is driven by the estimated change in private insurance payments.

An increase of $\$ 10$ in the patients' out-of-pocket payments received by the provider leads to a statistically significant decrease of 0.1369 percentage points in visits where patients' felt their provider spent enough time with them. The results show that there is a statistically significant decrease of 0.1819 percentage points in the visits where patients felt listened to and a statistically significant reduction of 0.1577 percentage points in the visits where patients felt respected by the providers, as the payments they made out-of-pocket to their providers increased by $\$ 10$.

In sum, there is no change in the providers' actual treatment decisions when the payments from the various sources change. However, the patients perceive a significant difference in the behavior of their medical care providers when the providers' payment sources change.

\section{TABLE 4 \\ IMPACT OF THE CHANGE IN PAYMENTS ON THE ACTUAL AND PERCEIVED BEHAVIORS OF MEDICAL CARE PROVIDERS}

\begin{tabular}{|c|c|c|c|c|c|c|}
\hline & \multicolumn{6}{|c|}{ Outcome Variables } \\
\hline & \multicolumn{3}{|c|}{ Providers' Treatment Decisions: } & \multicolumn{3}{|c|}{ Patients' Perception: } \\
\hline$\left(\frac{\alpha_{1}^{\text {(outcome })}}{\alpha_{1}^{\text {(treatment })}}\right)$ & $\begin{array}{c}\text { Any } \\
\text { Medicine } \\
\text { Prescribed } \\
(1)\end{array}$ & $\begin{array}{l}\text { Lab } \\
\text { Tests } \\
\text { (2) }\end{array}$ & $\begin{array}{c}\text { Other } \\
\text { Diag } \\
\text { Test/Exam } \\
(3)\end{array}$ & $\begin{array}{c}\text { Enough } \\
\text { Time } \\
\text { (4) }\end{array}$ & $\begin{array}{l}\text { Listen } \\
(5)\end{array}$ & $\begin{array}{c}\text { Respect } \\
\text { (6) }\end{array}$ \\
\hline Payment Variables: & & & & & & \\
\hline $\begin{array}{l}\text { Total Payment - All } \\
\text { Sources }(\$) \\
\text { Total Payment - Private } \\
\text { Ins \& Medicaid (\$) } \\
\text { Payment by Sources: }\end{array}$ & $\begin{array}{l}-0.4004 \\
(1.5755)\end{array}$ & $\begin{array}{r}-0.4338 \\
(1.701)\end{array}$ & $\begin{array}{l}-0.5006 \\
(1.9544)\end{array}$ & $\begin{array}{l}-0.8788 \\
(3.3994) \\
0.1038 * * \\
(0.0501)\end{array}$ & $\begin{array}{l}-1.1680 \\
(4.5093) \\
0.1379 * * * \\
(0.0535)\end{array}$ & $\begin{array}{l}-1.0122 \\
(3.9114) \\
0.1195 * * \\
(0.0560)\end{array}$ \\
\hline Out-of-Pocket (\$) & & & & $\begin{array}{c}-0.1369 * * \\
(0.0720)\end{array}$ & $\begin{array}{c}-0.1819 * * \\
(0.0800)\end{array}$ & $\begin{array}{c}-0.1577 * * \\
(0.0807)\end{array}$ \\
\hline Private insurance $(\$)$ & & & & $\begin{array}{c}0.0791 * * \\
(0.0361)\end{array}$ & $\begin{array}{l}0.1051 * * * \\
(0.0372)\end{array}$ & $\begin{array}{c}0.0911 * * \\
(0.0401)\end{array}$ \\
\hline Medicaid (\$) & & & & $\begin{array}{l}-0.3193 \\
(0.3045)\end{array}$ & $\begin{array}{l}-0.4244 \\
(0.3858)\end{array}$ & $\begin{array}{l}-0.3678 \\
(0.3479)\end{array}$ \\
\hline Others $(\$)$ & & & & $\begin{array}{l}-0.2992 \\
(0.2447)\end{array}$ & $\begin{array}{c}-0.3977 \\
(0.3044)\end{array}$ & $\begin{array}{c}-0.3447 \\
(0.2788)\end{array}$ \\
\hline
\end{tabular}




\begin{tabular}{lc}
\hline Year Controls & Yes \\
Region Controls & Yes \\
Condition Control & Yes \\
Observations & Yes \\
Weighted & 12 Months \\
Bandwidth & Notes. The standard errors are reported in brackets below the estimated coefficients. These standard errors are \\
clustered at the age level, measured in months. Clustered standard errors in brackets $(* * *$ p $<0.01, * *$ p $<0.05, *$ \\
p $<0.1)$. The effect of the change in payments on actual and perceived behaviors are calculated as Wald estimators. \\
That is, the estimated outcome variables are divided by the estimated treatment variable. The standard errors for \\
those Wald estimates are calculated using the propagation of error formulas. The model is estimated on a sample \\
within 12 months above and below the age 228-month threshold. The controls used in this model include year \\
indicators from 1996 to 2009 and the region indicators for Northeast, West, Midwest, and South regions.
\end{tabular}

\section{ROBUSTNESS CHECKS}

In this section, I discuss the sensitivity of my results to alternative bandwidths (section 5.1) and the sensitivity of the results to the outliers of the payments limits (section 5.2).

\section{Bandwidth Sensitivity}

The OLS estimates of the treatment and outcome variables are qualitatively the same for a wide range of bandwidths. Table 5 repeats the results for a twelve-month bandwidth and then reports the estimates with nine-month and fifteen-month bandwidths.

As shown in Table 5, the nine-month and 15-month bandwidths estimated discontinuities are qualitatively similar. When the bandwidth is nine months, the change in the total payments is $-\$ 2.165$, the difference in payments sourced from private insurance and Medicaid combined is $-\$ 9.052$, the change in out-of-pocket payments is $\$ 4.917$, and the change in payments sourced from private insurance is $-\$ 10.255$. When the bandwidth expands to fifteen months on either side of the threshold, the total payments, the payments sourced from Medicaid and private insurance combined, the out-of-pocket payments, and the private insurance payments change by $\$ 1.327,-\$ 7.046, \$ 5.366$, and $-\$ 10.366$, respectively. These are similar to the changes estimated with the main bandwidth of twelve months.

\section{Outlier Sensitivity}

Changing the limit with which I determined the outliers removed from my analysis sample does not change the qualitative estimates of the treatment and outcome variables using the reduced form equation 1. Table 6 shows that these point estimates for an analysis sample without the outliers in the 80th percentile (approximately \$100) and the 90th percentile (roughly \$200) of the total payment variable are qualitatively similar. 
TABLE 5

ROBUSTNESS CHECKS - BANDWIDTH SENSITIVITY

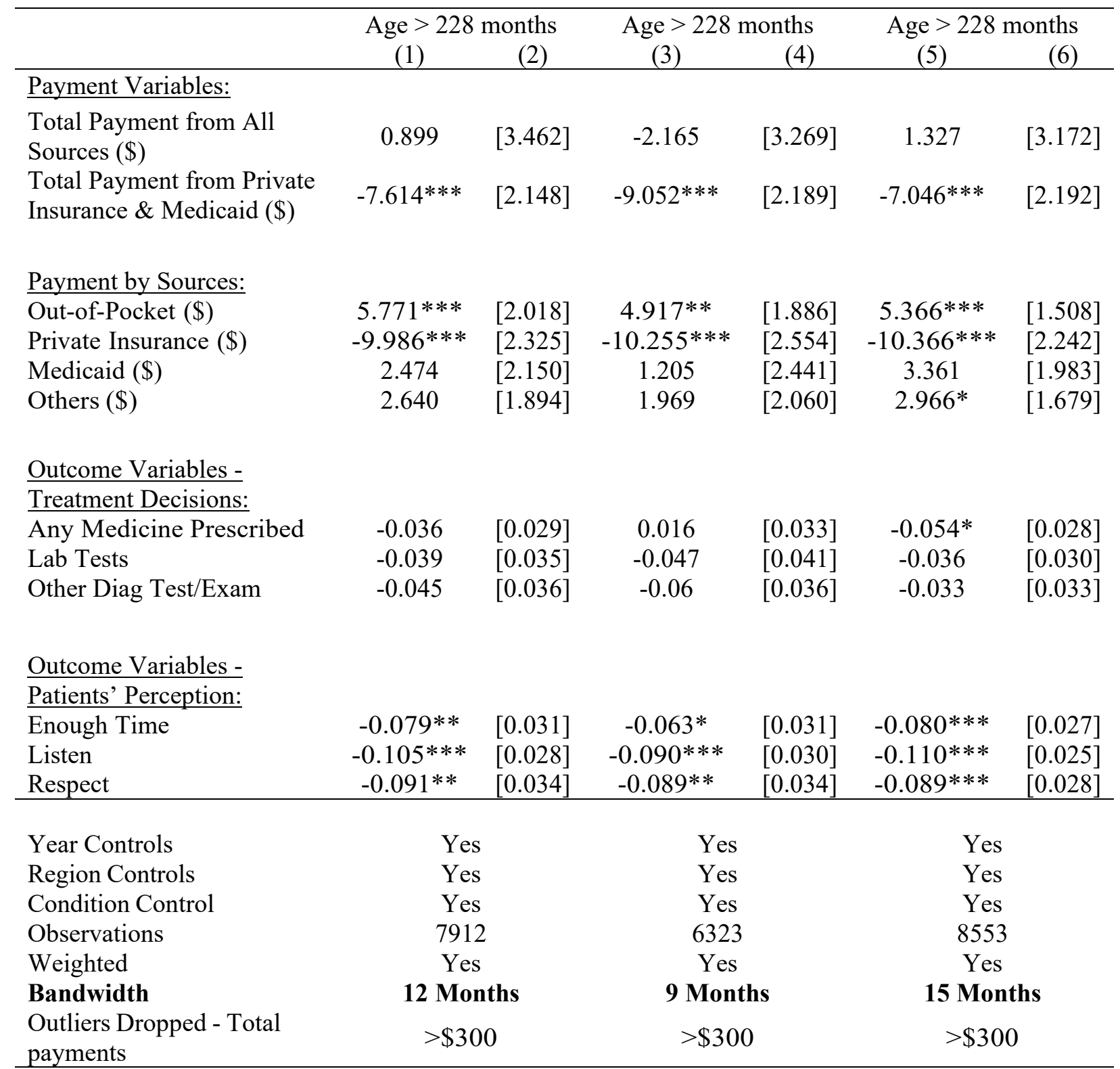

Notes. The standard errors are reported in brackets next to the estimated coefficients. These standard errors are clustered at the age level, measured in months. Clustered standard errors in brackets $(* * * \mathrm{p}<0.01, * * \mathrm{p}<0.05, *$ $\mathrm{p}<0.1$ ). The model is estimated on a sample within 12 months above and below the age 228 months threshold. The control variables used in these regression models include year indicator variables for the years 1996 to 2009, region indicator variables for the Northeast, West, Midwest, and South regions. The demographic variables of the individuals in the sample controlled in the model are gender, race, socio-economic status, ethnicity, and employment status. The conditions addressed during each visit as categorized by ICD9 codes are also controlled for in the model. The data are weighted using the reported final person weight assigned to everyone. The data is sourced from MEPS administered by AHRQ. 
TABLE 6

ROBUSTNESS CHECKS - OUTLIER SENSITIVITY

\begin{tabular}{|c|c|c|c|c|c|c|}
\hline & \multicolumn{2}{|c|}{$\begin{array}{c}\text { Approx. } \\
\text { 95th Percentile } \\
\text { Age }>228 \text { months }\end{array}$} & \multicolumn{2}{|c|}{$\begin{array}{c}\text { Approx. } \\
\text { 85th Percentile } \\
\text { Age }>228 \text { months }\end{array}$} & \multicolumn{2}{|c|}{$\begin{array}{c}\text { Approx. } \\
\text { 90th Percentile } \\
\text { Age }>228 \text { months }\end{array}$} \\
\hline & (1) & $(2)$ & (3) & $(4)$ & $(5)$ & $(6)$ \\
\hline \multicolumn{7}{|l|}{ Payment Variables: } \\
\hline $\begin{array}{l}\text { Total Payment from All } \\
\text { Sources }(\$)\end{array}$ & 0.899 & {$[3.462]$} & 0.661 & [1.848] & 0.691 & [1.733] \\
\hline $\begin{array}{l}\text { Total Payment from Private } \\
\text { Insurance \& Medicaid (\$) }\end{array}$ & $-7.614 * * *$ & {$[2.148]$} & $-3.378 * *$ & {$[1.544]$} & $-6.499 * *$ & [2.615] \\
\hline \multicolumn{7}{|l|}{ Payment by Sources: } \\
\hline Out-of-Pocket (\$) & $5.771 * * *$ & {$[2.018]$} & $4.087 * * *$ & {$[1.177]$} & $4.693 * * *$ & {$[1.498]$} \\
\hline Private Insurance (\$) & $-9.986 * * *$ & {$[2.325]$} & $-4.747 * *$ & [2.265] & $-8.119 * *$ & [3.036] \\
\hline Medicaid (\$) & 2.474 & {$[2.150]$} & 1.451 & [1.641] & 1.729 & [2.053] \\
\hline Others $(\$)$ & 2.640 & {$[1.894]$} & -0.131 & {$[1.107]$} & 2.389 & [1.449] \\
\hline \multicolumn{7}{|l|}{ Outcome Variables - } \\
\hline$\overline{\text { Any Medicine Prescribed }}$ & -0.036 & {$[0.029]$} & -0.042 & {$[0.033]$} & -0.044 & [0.031] \\
\hline Lab Tests & -0.039 & {$[0.035]$} & -0.045 & {$[0.035]$} & -0.032 & [0.033] \\
\hline Other Diag Test/Exam & -0.045 & {$[0.036]$} & -0.03 & {$[0.040]$} & -0.034 & {$[0.037]$} \\
\hline \multicolumn{7}{|l|}{ Outcome Variables - } \\
\hline Enough Time & $-0.079 * *$ & [0.031] & $-0.070 *$ & {$[0.040]$} & $-0.070 *$ & [0.034] \\
\hline Listen & $-0.105 * * *$ & {$[0.028]$} & $-0.105 * * *$ & [0.029] & $-0.097 * * *$ & [0.027] \\
\hline Respect & $-0.091 * *$ & {$[0.034]$} & $-0.087 * *$ & {$[0.041]$} & $-0.087 * *$ & [0.035] \\
\hline Year Controls & \multicolumn{2}{|c|}{ Yes } & \multicolumn{2}{|c|}{ Yes } & \multicolumn{2}{|c|}{ Yes } \\
\hline Region Controls & \multicolumn{2}{|c|}{ Yes } & \multicolumn{2}{|c|}{ Yes } & \multicolumn{2}{|c|}{ Yes } \\
\hline Condition Control & \multicolumn{2}{|c|}{ Yes } & \multicolumn{2}{|c|}{ Yes } & \multicolumn{2}{|c|}{ Yes } \\
\hline Observations & \multicolumn{2}{|c|}{7912} & \multicolumn{2}{|c|}{6291} & \multicolumn{2}{|c|}{7578} \\
\hline Weighted & \multicolumn{2}{|c|}{ Yes } & \multicolumn{2}{|c|}{ Yes } & \multicolumn{2}{|c|}{ Yes } \\
\hline Bandwidth & \multicolumn{2}{|c|}{12 Months } & \multicolumn{2}{|c|}{12 Months } & \multicolumn{2}{|c|}{12 Months } \\
\hline $\begin{array}{l}\text { Outliers Dropped - Total } \\
\text { payments }\end{array}$ & \multicolumn{2}{|c|}{$>\$ 300$} & \multicolumn{2}{|c|}{$>\$ 100$} & \multicolumn{2}{|c|}{$>\$ 200$} \\
\hline
\end{tabular}

Notes. The standard errors are reported in brackets next to the estimated coefficients. These standard errors are clustered at the age level, measured in months. Clustered standard errors in brackets $(* * * \mathrm{p}<0.01, * * \mathrm{p}<0.05, *$ $\mathrm{p}<0.1$ ). The model is estimated on a sample within 12 months above and below the age 228 months threshold. The control variables used in these regression models include year indicator variables for the years 1996 to 2009, region indicator variables for the Northeast, West, Midwest, and South regions. The demographic variables of the individuals in the sample controlled in the model are gender, race, socio-economic status, ethnicity, and employment status. The conditions addressed during each visit as categorized by ICD9 codes are also controlled for in the model. The data are weighted using the reported final person weight assigned to each individual. The data is sourced from MEPS administered by AHRQ. 


\section{DISCUSSION}

This paper finds a statistically significant drop of $16.33 \%$ in payments that results from the reduction in private and public (Medicaid) insurance coverage, with a decline of 37.96\% in payments sourced from private insurance. On the other hand, there is a statistically significant increase of $45.87 \%$ in the out-ofpocket payment source. These results reflect the drop in insurance coverage among the young adults that occurred due to young adults aging out of their parents' insurance at 228 months (Collins et al., 2008; Schwartz and Damico, 2010; Palmieri, 2017). Despite the change in the sources of the total payment, my results showed no change in the actual treatment decisions of the medical care providers. However, my additional results indicate that patients perceive a difference in their medical care providers' behavior. The patients felt that their providers did not spend enough time with them and felt less respected. The patients felt less listened to by their medical care providers.

The result from the reduced form estimates of the treatment and outcome variables allowed for the causal estimation of the effect of the change in payments on the actual and patient-perceived behaviors of the medical care providers. As the mix of the payments received by medical care providers changed, their actual treatment decisions did not change. However, the patients' perception of their providers' behaviors changed as these payment sources changed. Implying that the patient's expected more from their medical care providers as the out-of-pocket payments they made increased.

The 2018 repeal of the individual mandate portion of the Patient Protection and Affordable Care Act (PPACA) allows for a drop in private health insurance coverage in the economy. Most of the decrease comes from the non-elderly adult population, of which the nineteen-year-olds are a relevant proxy (Anderson et al., 2012). As estimated in this paper, this leads to significant changes in the sources of the payments received by medical care providers. Therefore, given that the patient's perception of their providers is increasingly considered a cornerstone of good health care delivery (Clever et al., 2008), my results shown and discussed above highlight the importance of considering how these patient perceptions change as the payment structure of their medical care providers' changes.

\section{ENDNOTES}

1. This component is from the household survey. Other event files are "Dental Visits" files, "Other Medical Expenses" files, "Hospital Inpatient Stays" files, "Emergency Room Visits" files, "Outpatient Visits" files, "Prescribed Medicines" files, "Home Health" files, and "Appendix to MEPS Event" files (AHRQ, 2017).

2. The Office-Based Provider Public Use Data File contains characteristics associated with the office-based visit, such as date of the visit, time spent with the provider, types of treatment and services received, types of medicine prescribed, condition codes, expenditures, and sources of payment associated with the visit (AHRQ and Quality, 2014).

3. Tests/Exams other than lab tests, such as in-depth physical exams and intricate personal information (and behavior) gathering - questioning

4. Given the bandwidth of twelve months, the individuals in the primary analysis are aged 216 months, 217, $218 \ldots, 228$ months, $229,230, \ldots$, and 240 months at the time of the office-based visit.

5. A detailed discussion of the Regression Discontinuity (RD) design and its related issues is put forward in Imbens and Lemieux (2008) and Lee and Lemieux (2010).

6. The other categories that comprise other than married are Separated, Divorced, Widowed, and Never Married.

7. ICD9 codes are The International Classification of Diseases, Ninth Revision, Clinical Modification (ICD-9$\mathrm{CM}$ ) is the US health system's adaptation of the international ICD-9 standard list of six-character alphanumeric codes to describe diagnoses. ICD-9-CM contains a list of codes corresponding to diagnoses and procedures recorded in conjunction with hospital care in the United States (Rouse, 2014).

8. Propagation of Error (or Propagation of Uncertainty) is defined as the effects on a function by a variable's uncertainty. It is a calculus derived statistical calculation designed to combine uncertainties from multiple variables to measure uncertainty accurately. 


\section{REFERENCES}

AHRQ. (2008). MEPs hc-104 - medical conditions.

AHRQ, A. f. H. R. (2009). Medical expenditure panel survey background.

AHRQ, A. f. H. R. (2014). Medical expenditure panel survey public use file details.

AHRQ, A. f. H. R. (2015). Medical expenditure panel survey questionnaires.

AHRQ, A. f. H. R. (2017). Medical expenditure panel survey downloads data files.

AHRQ, A. f. H. R. (2018). Medical expenditure panel survey home.

AHRQ, A. f. H. R. and Quality (2014). Medical expenditure panel survey public use file details.

Almond, D., Doyle, J.J., Jr., Kowalski, A.E., \& Williams, H. (2010). Estimating marginal returns to medical care: Evidence from at-risk newborns*. The Quarterly Journal of Economics, 125(2), 591-634.

Anderson, M., Dobkin, C., \& Gross, T. (2012). The effect of health insurance coverage on the use of medical services. American Economic Journal: Economic Policy, 4(I), 1-27.

Andrews, M. (2013). Options for young adults: Stay on the folks' plan, move to the marketplace or go without.

Boquiren, V.M., Hack, T.F., Beaver, K., \& Williamson, S. (2015). What do measures of patient satisfaction with the doctor tell us? Patient Education and Counseling, 98(12), 1465-1473.

Cameron, A.C., \& Trivedi, P.K. (2017). Microeconometrics Methods and Applications. Cambridge University Press.

Chemistry-LibreTexts. (2018). Propagation of error.

Clever, S.L., Jin, L., Levinson, W., \& Meltzer, D.O. (2008). Does doctor-patient communication affect patient satisfaction with hospital care? Results of an analysis with a novel instrumental variable. Health Services Research, 43(5p1), 1505-1519.

Cohen, J.W., Cohen, S.B., \& Banthin, J.S. (2009). The medical expenditure panel survey. Medical Care, 47(Supplement), S44-S50.

Collins, S.R., Schoen, C., Kriss, J.L., Gould, E.M., \& Mahato, B. (2008). Rite of passage? Why young adults become uninsured and how new policies can help. Commonwealth Fund Issue Briefs, 38, 1-24.

Freeman, T. (2002). Using performance indicators to improve health care quality in the public sector: A review of the literature. Health Services Management Research, 15(2), 126137.

Harrison, J.M., Lagisetty, P., Sites, B.D., Guo, C., \& Davis, M.A. (2018). Trends in prescription pain medication use by race/ethnicity among us adults with noncancer pain, 2000-2015. American Journal of Public Health, 108(6), 788-790.

Healthcare.gov. (2012). Health insurance coverage for children and young adults under 26.

Imbens, G.W., \& Lemieux, T. (2008). Regression discontinuity designs: A practice guide. Journal of Econometrics, 142(2), 615-635.

Kupfer, J.M., \& Bond, E.U. (2012). Patient satisfaction and patient-centered care. Jama, 308(2), 139.

Lee, D.S., \& Card, D. (2008). Regression discontinuity inference with specification error. Journal of Econometrics, 142(2), 655-674.

Lee, D.S., \& Lemieux, T. (2010). Regression discontinuity designs in economics. Journal of Economic Literature, 48(2), 281-355.

McCrary, J. (2007). Manipulation of the running variable in the regression discontinuity design: A density test. Working Paper 334, National Bureau of Economic Research.

Palmieri, G. (2017). Benefit spotlight: Milestone birthdays that matter for dental and vision coverage.

Riiskjær, E., Ammentorp, J., Nielsen, J.F., \& Kofoed, P-E. (2010). Patient surveys-a key to organizational change? Patient Education and Counseling, 78(3), 394-401.

Roffman, C.E., Buchanan, J., \& Allison, G.T. (2016). Charlson comorbidities index. Journal of Physiotherapy, 62(3), 171. 
Rouse, M. (2014). What is ICD-9-cm (international classification of diseases, ninth revision, clinical modification)? Definition from whatis.com.

Schmidheiny, K. (2018). Instrumental variables - Short guides to microeconometrics.

Schwartz, K., \& Damico, A. (2010). Aging out of Medicaid: What is the risk of becoming uninsured?

Squires, S. (2012). Patient satisfaction: How to get it and how to keep it. Nursing Management (Springhouse), 43(4), 26-32.

Trochim, W. (1984). Research Design for Program Evaluation: The Regression-Discontinuity Design. SAGE Publications, Inc.

Wang, L.Y., Zhong, Y., \& Wheeler, L. (2006). Asthma medication use in school-aged children. Journal of Asthma, 43(7), 495-499.

Zuckerman, I.H., Lee, E., Wutoh, A.K., Xue, Z., \& Stuart, B. (2006). Application of regressiondiscontinuity analysis in pharmaceutical health services research. Health Services Research, $41(2), 550-563$. 